\title{
Atomic layer deposition of vanadium oxide thin films from tetrakis(dimethylamino)vanadium precursor
}

\author{
Xinwei Wang, ${ }^{\text {a) }}$ Zheng Guo, Yuanhong Gao, and Jue Wang \\ School of Advanced Materials, Shenzhen Graduate School, Peking University, Shenzhen 518055, China
}

(Received 11 May 2016; accepted 3 August 2016)

\begin{abstract}
Atomic layer deposition (ALD) of vanadium oxide $\left(\mathrm{VO}_{x}\right)$ thin films, using tetrakis(dimethylamino)vanadium as the vanadium precursor, is comprehensively reported in this work. The vanadium precursor is highly volatile and can be used at room temperature for deposition. Either $\mathrm{H}_{2} \mathrm{O}$ or $\mathrm{O}_{3}$ can be used as the coreactant for depositing $\mathrm{VO}_{x}$ at $50-200{ }^{\circ} \mathrm{C}$. However, partial precursor decomposition is suggested for the deposition temperature higher than $160{ }^{\circ} \mathrm{C}$. The as-deposited $\mathrm{VO}_{x}$ films are pure, smooth, and amorphous, and can be crystallized into monoclinic $\mathrm{VO}_{2}$ phase by postdeposition annealing under $\mathrm{N}_{2}$ ambient. The minimum annealing temperature for film to crystallize is found, by in situ high-temperature X-ray diffraction experiments, at around $550-600{ }^{\circ} \mathrm{C}$. In situ quartz crystal microbalance experiments are performed to further analyze the surface reaction mechanism involved in this ALD process.
\end{abstract}

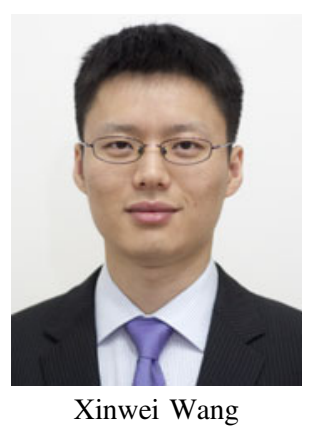

\begin{abstract}
Xinwei Wang is currently an Assistant Professor at School of Advanced Materials, Shenzhen Graduate School, Peking University, China. He received his Bachelor degree in Physics from Peking University, China, in 2008, and his Ph.D. degree in Chemical Physics from Harvard University in 2012. After a short period of postdoctoral research at Harvard University, he joined the faculty of Peking University in 2013. His research has been mainly focused on ALD for thin film materials, with the emphasis on the development of new ALD processes and their applications for energy and microelectronic devices. He has published more than 30 peer-reviewed papers in this field.
\end{abstract}

\section{INTRODUCTION}

Vanadium oxide $\left(\mathrm{VO}_{x}\right)$ has been extensively studied for many decades, due to its polymorphism and wide applications in a variety of fields. ${ }^{1}$ The properties of $\mathrm{VO}_{x}$ are closely related to its stoichiometry, crystal structure, and morphology. ${ }^{1}$ Among various $\mathrm{VO}_{x}$ compounds, $\mathrm{VO}_{2}$ and $\mathrm{V}_{2} \mathrm{O}_{5}$ are particularly important for studying. Vanadium atoms in $\mathrm{VO}_{2}$ and $\mathrm{V}_{2} \mathrm{O}_{5}$ are in their +4 and +5 oxidation states, respectively. $\mathrm{VO}_{2}$ is featured for its well-known metal-insulator transition near $67{ }^{\circ} \mathrm{C} .^{2}$ This transition leads to an abrupt reduction in resistivity and infrared transmission, and therefore renders $\mathrm{VO}_{2}$ promising for nanoelectronic switches, ${ }^{3}$ transistors, ${ }^{4}$ and optical devices. ${ }^{5} \mathrm{~V}_{2} \mathrm{O}_{5}$ also has a fairly wide scope of applications. Examples include cathode materials for lithium-ion batteries ${ }^{6}$ and sodiumion batteries, ${ }^{7}$ active materials for supercapacitors, ${ }^{8,9}$

Contributing Editor: Edson Roberto Leite

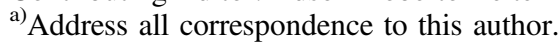

e-mail: wangxw@pkusz.edu.cn

DOI: $10.1557 / j m r .2016 .303$ charge-injection-layer materials for field-effect transistors, ${ }^{10}$ and catalysts for organic synthesis. ${ }^{11}$

Synthesis techniques for $\mathrm{VO}_{x}$ thin films are of great importance to realize the material applications. Over the years, various preparation approaches have been developed for $\mathrm{VO}_{x}$ thin films, such as sol-gel, ${ }^{12}$ spray pyrolysis, ${ }^{13}$ electrodeposition, ${ }^{14}$ evaporation, ${ }^{15}$ magnetron sputtering, ${ }^{16}$ pulsed laser deposition, ${ }^{17}$ chemical vapor deposition, ${ }^{18}$ and atomic layer deposition (ALD). ${ }^{6,8,19-32}$ Among these approaches, ALD is of particular interest for preparing thin films. ALD employs alternate saturated self-limiting surface chemistry reactions, and allows one to deposit thin films in a well-controlled layer-by-layer fashion. ${ }^{33}$ The properties of ALD films, such as composition, crystal structure, and morphology, are highly consistent, reproducible, and uniform over large area, and meanwhile the thickness of deposited films can be precisely controlled at an atomic level by digitally adjusting the total ALD cycles. Moreover, ALD also allows for conformal thin-film coating on high aspect-ratio 3D structures, which is essential 
for realizing the above-mentioned high-performance batteries/supercapacitors applications ${ }^{6,8,9}$ as well as various other applications. ${ }^{34-36}$

ALD of $\mathrm{VO}_{x}$ has been reported using several types of vanadium precursors. Vanadyl triisopropoxide was a commonly used vanadium precursor, ${ }^{6,8,19-23}$ and was applied for both thermal (with water ${ }^{6,19-21}$ or ozone ${ }^{8,22}$ ) and plasma-enhanced ${ }^{23}$ ALD processes. A similar precursor, vanadium n-propoxide, could also be used along with acetic acid to produce ALD $\mathrm{V}_{2} \mathrm{O}_{4} \cdot{ }^{24} \mathrm{Also}$, $\mathrm{VOCl}_{3}$ could be used with water to deposit $\mathrm{VO}_{2}{ }^{25}$ $\beta$-diketonate-based precursors, such as $\mathrm{VO}(\mathrm{acac})_{2}$ (Ref. 26) (acac $=$ acetylacetonate) and $\mathrm{VO}(\text { thd })_{2}$ (Ref. 27) (thd $=$ 2,2,6,6-tetramethylheptane-3,5-dionate), were also reported for ALD with the combined use of oxygen $^{26}$ and ozone, ${ }^{27}$ respectively. Recently, an aminobased precursor of tetrakis(ethylmethylamino)vanadium [V(NEtMe $\left.)_{4}\right]$ was described with water or ozone for depositing $\mathrm{VO}_{x}$ thin films. ${ }^{28-30}$ In this case, since metalnitrogen bonds are generally weaker than metal-oxygen bonds in transition metal organic compounds, $\mathrm{V}(\mathrm{NEtMe})_{4}$ should be more reactive toward forming oxides in ALD. Also, $\mathrm{V}$ is in nominal +4 valence state in $\mathrm{V}(\mathrm{NEtMe})_{4}$, and it should be therefore more favorable for depositing stoichiometric $\mathrm{VO}_{2}$ thin films. ${ }^{31}$ Very recently, our group used another type of amino vanadium precursor, tetrakis (dimethylamino)vanadium $\left[\mathrm{V}(\mathrm{dma})_{4}\right]$, with water, and were able to deposit $\mathrm{VO}_{x}$ at a fairly low temperature of $50{ }^{\circ} \mathrm{C} .{ }^{32}$ The deposited $\mathrm{VO}_{x}$ thin film showed great charge injection performance for organic field-effect transistor devices. ${ }^{32}$

In this paper, we present a detailed study of ALD $\mathrm{VO}_{x}$ from this $\mathrm{V}(\mathrm{dma})_{4}$ precursor. The deposition temperature was largely extended up to $200{ }^{\circ} \mathrm{C}$, and both ozone and water were investigated as the corresponding oxygen source. Careful material characterizations were performed on the films deposited under various conditions. Postdeposition annealing was also attempted to crystallize the amorphous as-deposited films. In situ quartz crystal microbalance (QCM) measurements were also performed to analyze the surface reaction mechanism involved in this ALD process. With these detailed characterizations, we hope to provide a comprehensive view of $\mathrm{VO}_{x} \mathrm{ALD}$ process from this $\mathrm{V}(\mathrm{dma})_{4}$ precursor.

\section{EXPERIMENTAL SECTION}

\section{A. ALD of vanadium oxide films}

Vanadium oxide films were deposited in a home-built tubular ALD reactor. Tetrakis(dimethylamino)vanadium $\left[\mathrm{V}(\mathrm{dma})_{4}\right]$ was used as the vanadium precursor, and water vapor or ozone was used as the coreactant gas. Water and $\mathrm{V}(\mathrm{dma})_{4}$ were both kept at room temperature in two separate glass containers, respectively. Note that $\mathrm{V}(\mathrm{dma})_{4}$ is volatile and highly reactive with air and moisture, and thus it should be handled (e.g., loading into the glass container) in an inert gas filled glovebox with great care. Ozone was produced by an ozone generator from pure $\mathrm{O}_{2}\left(40 \mathrm{mg} / \mathrm{L}, \sim 3 \%\right.$ in $\left.\mathrm{O}_{2}\right)$. During the deposition, the vanadium precursor was delivered into the deposition chamber with the assistance of $\mathrm{N}_{2}$ carrier gas. As for the water vapor or ozone, it was first delivered into a $\sim 5 \mathrm{~mL}$ gas trap and then delivered into the deposition chamber for depositing films. The base pressure of the deposition chamber was $\sim 0.3$ Torr during the step of purging with $\mathrm{N}_{2}$. All the $\mathrm{N}_{2}$ was purified through a Gatekeeper inert gas purifier. The deposition temperature was varied from 50 to $200{ }^{\circ} \mathrm{C}$. Flow-through mode was used for all the ALD processes. A long purging time of $100 \mathrm{~s}$ was used after each precursor dose, allowing for a complete removal of the by-products as well as unreacted excess precursors. Si wafer and fused silica substrates were used for deposition studies. Both the substrates were treated with ultraviolet/ozone for $5 \mathrm{~min}$ before deposition, and the native oxide on $\mathrm{Si}$ was not intentionally removed.

\section{B. Characterizations of precursor and $\mathrm{VO}_{x}$ films}

Thermogravimetric (TG) analyses were performed on a Mettler-Toledo TGA-2 system (Schwerzenbach, Switzerland) under $\mathrm{N}_{2}$ ambient inside a glovebox. Approximately $10 \mathrm{mg}$ of $\mathrm{V}(\mathrm{dma})_{4}$ sample was used for each measurement. $50 \mathrm{sccm}$ of $\mathrm{N}_{2}$ gas was used as the flow gas, and the temperature ramping rate was set as $10{ }^{\circ} \mathrm{C} / \mathrm{min}$. Both open-cup and close-cup modes were used for the TG measurements. Under close-cup condition, the sample crucible was covered by a lid with a pinhole of $1 \mathrm{~mm}$ diameter, which could slow down the release of $\mathrm{V}$ $(\mathrm{dma})_{4}$ vapor and allow the precursor to be exposed to a higher temperature for evaluating its thermal stability.

The thickness of the deposited $\mathrm{VO}_{x}$ films was measured by X-ray reflectometry (XRR) using parallel (Göbel mirror) $\mathrm{Cu} \mathrm{K} \alpha$ radiation (D8 Advance, Bruker Corporation, Karlsruhe, Germany). The film composition was analyzed by X-ray photoelectron spectroscopy (XPS) using monochromated $\mathrm{Al} \mathrm{K}_{\alpha}$ radiation (Escalab 250Xi, Thermo Fisher Scientific, East Grinstead, United Kingdom). The pass energies for survey and high-resolution scans were 50 and $20 \mathrm{eV}$, respectively. To remove the adventitious carbon on sample surface, $20 \mathrm{~s}$ of $2 \mathrm{keV} \mathrm{Ar}^{+}$sputtering was performed prior to each XPS measurement. X-ray diffraction (XRD) was used to analyze the film crystallinity. Regular XRD experiments were performed on the same Bruker diffractometer as for XRR. In situ hightemperature XRD (HTXRD) was performed on a Rigaku SmartLab diffractometer (Rigaku Corporation, Tokyo, Japan) equipped with an Anton-Paar oven under $\mathrm{N}_{2}$ ambient. The HTXRD spectra were taken at temperatures ranging from 200 to $800{ }^{\circ} \mathrm{C}$ in steps of $50{ }^{\circ} \mathrm{C}$. The temperature ramping rate was set as $10{ }^{\circ} \mathrm{C} / \mathrm{min}$, and additional 10 min waiting time was set to stabilize the 
temperature before taking each spectrum. Atomic force microscopy (AFM; MultiMode 8, Bruker Corporation, Santa Barbara, California) and scanning electron microscopy (SEM; SUPRA55, Carl Zeiss AG, Oberkochen, Germany) were used to examine the film surface morphology. QCM was used to in situ investigate the reaction mechanism. The QCM consisted of a gold-covered quartz crystal sensor with an oscillation frequency of $\sim 6 \mathrm{MHz}$, and the change of the frequency was monitored by an Inficon SQC-310 controller (East Syracuse, New York).

\section{RESULTS AND DISCUSSION}

TG analysis was used to evaluate the volatility and thermal stability of the vanadium precursor $\mathrm{V}(\mathrm{dma})_{4}$. The TG experiments were performed under both open-cup and close-cup conditions. As shown in Fig. 1, the curves exhibited only a single step of weight loss, indicating a favorable single-step evaporation process upon heating. In particular, the TG weight loss started at a fairly low temperature under open-cup condition ( $1 \%$ weight loss at $70{ }^{\circ} \mathrm{C}$ ) and completed at $\sim 160{ }^{\circ} \mathrm{C}$, with only $\sim 2.5 \%$ in residual mass at the end of temperature ramping. This suggested that $\mathrm{V}(\mathrm{dma})_{4}$ is a highly volatile compound with sufficient thermal stability to serve as a suitable precursor for ALD. Moreover, $\mathrm{V}(\mathrm{dma})_{4}$ is comparatively much more volatile than $\mathrm{V}(\mathrm{NEtMe})_{4}$, a previously reported ${ }^{28}$ vanadium precursor which has a similar chemical structure as $\mathrm{V}$ $(\mathrm{dma})_{4}$. The TG weight loss for $\mathrm{V}(\mathrm{NEtMe})_{4}$ was reported to finish at $\sim 210{ }^{\circ} \mathrm{C}$, and its evaporation temperature was set as $65{ }^{\circ} \mathrm{C}$ during $\mathrm{ALD} .^{28}$ In our case, $\mathrm{V}(\mathrm{dma})_{4}$ completed weight loss at a much lower temperature around $160{ }^{\circ} \mathrm{C}$, and therefore we expected (validated later) that room temperature should be enough to provide sufficient $\mathrm{V}$ $(\mathrm{dma})_{4}$ vapor for ALD. Thus, no additional heating is needed for this precursor, which can greatly simplify the design of ALD reactors for future large-scale applications. On the other hand, it was also suggested that $\mathrm{V}(\mathrm{dma})_{4}$

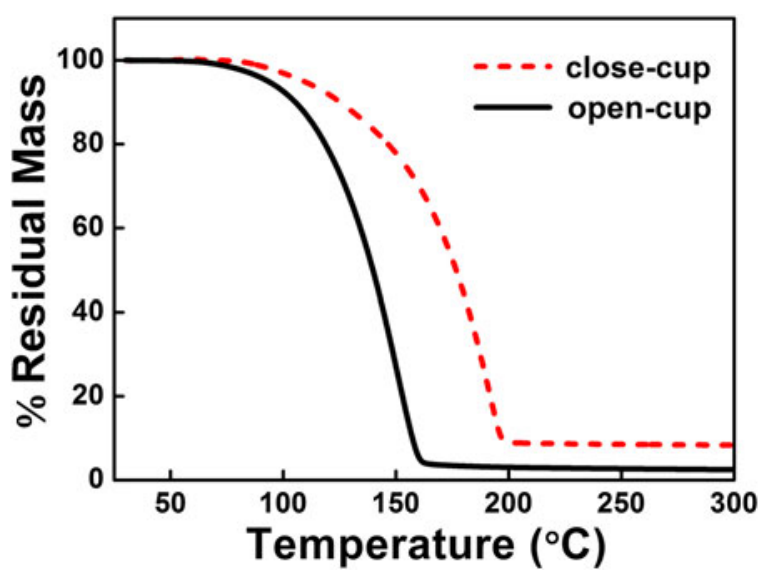

FIG. 1. TG curves of $\mathrm{V}(\mathrm{dma})_{4}$ performed under open-cup and closecup conditions. might partially decompose during high-temperature ALD $\left(>190{ }^{\circ} \mathrm{C}\right)$, since the TG curve under close-cup condition showed an appreciably higher residual mass $(8 \%$ above $200{ }^{\circ} \mathrm{C}$ ), which was likely from the thermal decomposition.

ALD of vanadium oxide thin films were performed following the procedure described in the Experimental Section. As we previously demonstrated for the deposition at $50{ }^{\circ} \mathrm{C},{ }^{32}$ single doses for both $\mathrm{V}(\mathrm{dma})_{4}$ and $\mathrm{H}_{2} \mathrm{O}$ were sufficient to, respectively, provide enough precursor exposures to saturate the ALD surface reactions. We therefore continued to use single doses for the precursors in this study. The equivalent exposures for single doses were roughly 0.02 and 0.05 Torr s for $\mathrm{V}(\mathrm{dma})_{4}$ and $\mathrm{H}_{2} \mathrm{O}$, respectively. Single dose was also used for $\mathrm{O}_{3}$, which corresponded to 0.03 Torr $\mathrm{s}$ in exposure, assuming negligible decomposition of $\mathrm{O}_{3}$ during delivering. The temperature dependence of the $\mathrm{VO}_{x}$ film growth rate is plotted in Fig. 2. The growth rates remained fairly constant up to $120{ }^{\circ} \mathrm{C}$, but substantially increased above $160{ }^{\circ} \mathrm{C}$, which was likely due to partial thermal decomposition at higher temperatures. Below $120{ }^{\circ} \mathrm{C}$, the $\mathrm{VO}_{x}$ growth rate using $\mathrm{O}_{3}$ as the oxygen source was $\sim 0.045 \mathrm{~nm} /$ cycle, which was $\sim 50 \%$ higher than the growth rate using $\mathrm{H}_{2} \mathrm{O}(\sim 0.030 \mathrm{~nm} /$ cycle $)$.

The chemical composition of the deposited $\mathrm{VO}_{x}$ films were examined by XPS. The XPS signals were collected on the $\mathrm{VO}_{x}$ samples with $20 \mathrm{~s}$ of $\mathrm{Ar}^{+}$sputtering to remove the adventitious carbon on surface. Figure 3 displays a set of representative spectra for a $15 \mathrm{~nm}$ film deposited at $120{ }^{\circ} \mathrm{C}$ using $\mathrm{H}_{2} \mathrm{O}$ as the coreactant. The survey spectrum [Fig. 3(a)] shows that the deposited film contained the elements of $\mathrm{V}, \mathrm{O}, \mathrm{C}, \mathrm{N}$, and $\mathrm{Ar}$, where the impurities of $\mathrm{C}$ and $\mathrm{N}$ were likely from the amino ligand of $\mathrm{V}(\mathrm{dma})_{4}$, and $\mathrm{Ar}$ was from the sputtering cleaning process. Highresolution XPS scans for $\mathrm{V}, \mathrm{O}, \mathrm{C}$, and $\mathrm{N}$ were also performed, and the spectra are shown in Figs. 3(b)-3(e). The elemental atomic percentages of the films deposited under various conditions were further extracted from the

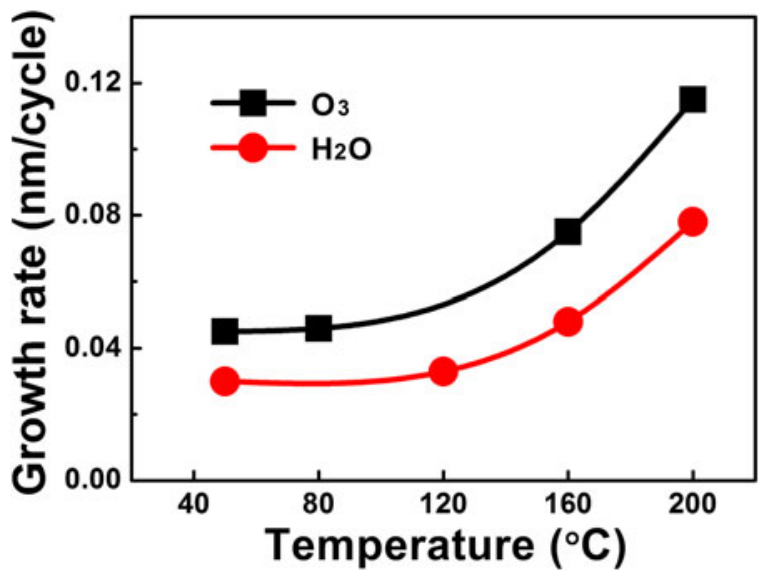

FIG. 2. Growth rate of $\mathrm{VO}_{x}$ films as a function of the deposition temperature. Water vapor or ozone was used as the oxygen source. 


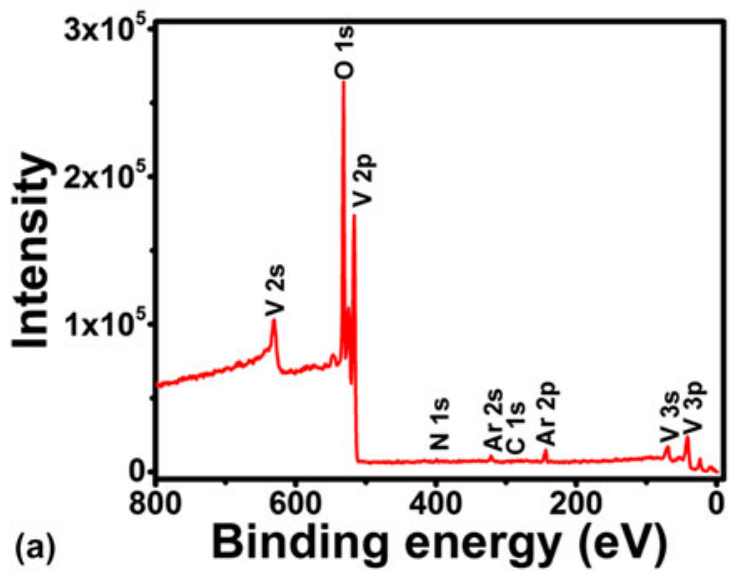

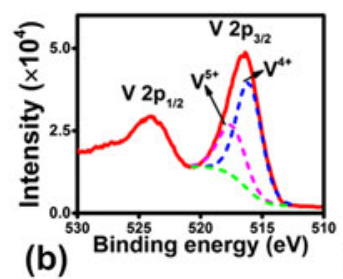

(b)
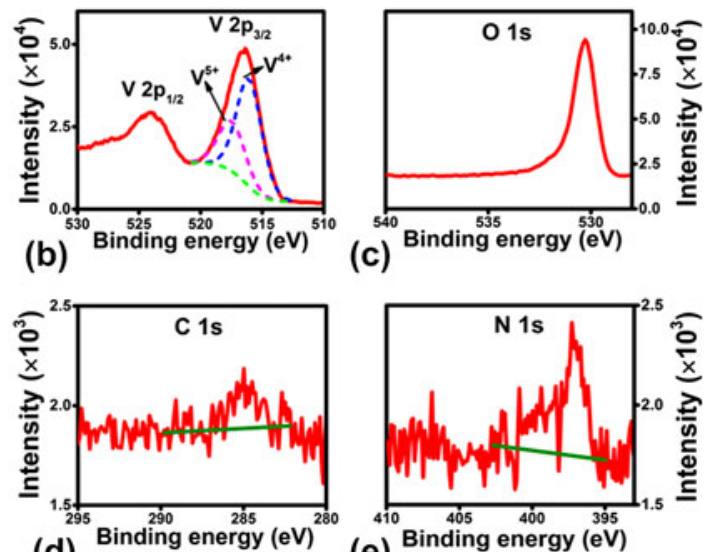

(d)

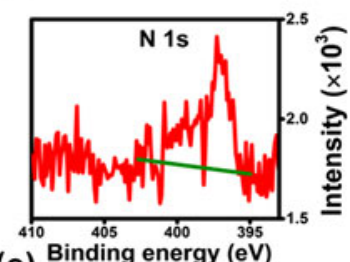

(e)

FIG. 3. Representative XPS results for a $15 \mathrm{~nm} \mathrm{VO}$ film deposited at $120^{\circ} \mathrm{C}$ with $\mathrm{H}_{2} \mathrm{O}$ as the coreactant. (a) Survey and high-resolution scans for (b) $\mathrm{V} 2 p$, (c) $\mathrm{O} 1 s$, (d) $\mathrm{C} 1 s$, and (e) $\mathrm{N} 1 s$, respectively.

XPS data and listed in Table I. For all these deposition conditions, both the $\mathrm{C}$ and $\mathrm{N}$ impurity levels were fairly low $\left(<3\right.$ at.\%), suggesting that the deposited $\mathrm{VO}_{x}$ films were fairly pure. The atomic ratios of $\mathrm{O} / \mathrm{V}$ were also included in Table I. Pure $\mathrm{VO}_{2}$ and $\mathrm{V}_{2} \mathrm{O}_{5}$ should have $\mathrm{O} / \mathrm{V}$ ratios of 2 and 2.5, respectively. However, the measured ratios were all between 2 and 2.5, without any clear trends on the deposition conditions. Similar results were also obtained with the use of $\mathrm{V}(\mathrm{NEtMe})_{4}$ as the vanadium precursor. ${ }^{28}$ It should be noted that the film oxygen content could also be affected by post oxidation after the films were exposed to air, and also, incorporation of water and/or unreacted hydroxyl groups during deposition could deviate the oxygen content from ideal stoichiometry as well. Deconvolution of the high-resolution $\mathrm{V} 2 p_{3 / 2}$ spectrum [Fig. 3(b)] suggested the presence of both $\mathrm{V}^{4+}(516.2 \mathrm{eV})$ and $\mathrm{V}^{5+}(517.6 \mathrm{eV})$ in the film, ${ }^{37}$ but further attempts to quantify the $\mathrm{V}^{4+} / \mathrm{V}^{5+}$ ratio were found to involve too much uncertainty to draw any solid conclusions. ${ }^{28}$

All the as-deposited $\mathrm{VO}_{x}$ films were amorphous, as there were no peaks in their XRD spectra. The films were also quite smooth. As examined by AFM, the rms roughness was only $\sim 0.32 \mathrm{~nm}$ for the films (approximately $10 \mathrm{~nm}$ in thickness) deposited with water at 50 or $120{ }^{\circ} \mathrm{C}$. The films deposited with ozone was slightly rougher, with the rms roughness around $1.0 \mathrm{~nm}$ for the films deposited at 50 or $80{ }^{\circ} \mathrm{C}$. Representative AFM images are shown in Fig. 4. Notice that no grain-like features were observed by AFM, which was consistent with the amorphous nature of these films. ${ }^{38}$

Postdeposition annealing was attempted to crystallize the amorphous $\mathrm{VO}_{x}$ films. As suggested by previous reports, ${ }^{28,31}$ we performed the annealing under $\mathrm{N}_{2}$ ambient, aiming to form crystalline $\mathrm{VO}_{2}$ films. Several ALD $\mathrm{VO}_{x}$ films deposited with $\mathrm{H}_{2} \mathrm{O}$ at $50{ }^{\circ} \mathrm{C}$ on fused silica substrates were used for this annealing study. The film thickness ranged from 30 to $60 \mathrm{~nm}$, with no observable
TABLE I. Elemental composition of the $\mathrm{VO}_{x}$ films deposited under various conditions (Data were extracted from XPS results).

\begin{tabular}{lcccccc}
\hline \hline Coreactant & $\begin{array}{c}\text { Deposition } \\
\text { Temperature }\left({ }^{\circ} \mathrm{C}\right)\end{array}$ & $\begin{array}{c}\mathrm{C} \\
(\text { at.\%) }\end{array}$ & $\begin{array}{c}\mathrm{N} \\
\text { (at.\%) }\end{array}$ & $\begin{array}{c}\mathrm{V} \\
(\text { at.\%) }\end{array}$ & $\begin{array}{c}\mathrm{O} \\
(\text { at.\%) }\end{array}$ & $\begin{array}{c}\mathrm{O} / \mathrm{V} \\
\text { ratio }\end{array}$ \\
\hline \multirow{3}{*}{$\mathrm{H}_{2} \mathrm{O}$} & 50 & 0.9 & 1.7 & 31.3 & 66.1 & 2.11 \\
& 120 & 0.6 & 0.9 & 30.9 & 67.6 & 2.19 \\
& 160 & 0.9 & 0.7 & 32.4 & 66.0 & 2.03 \\
$\mathrm{O}_{3}$ & 50 & 1.4 & 2.2 & 30.0 & 66.4 & 2.21 \\
& 80 & 2.5 & 1.6 & 29.2 & 66.7 & 2.28 \\
& 160 & 0.7 & 0.8 & 32.5 & 66.0 & 2.03 \\
\hline \hline
\end{tabular}

difference in this study. After $2 \mathrm{~h}$ annealing at $800{ }^{\circ} \mathrm{C}$ under $\mathrm{N}_{2}$, we found that the amorphous $\mathrm{VO}_{x}$ films indeed converted to a monoclinic phase of $\mathrm{VO}_{2}$ (PDF\#44-0252). The XRD spectra of the film before and after the annealing are comparatively shown in Fig. 5. On the other hand, the film showed severe agglomeration after the annealing; the film became discontinuous and formed submicron-sized islands (Fig. 6). To better understand the temperature effect during annealing, we performed in situ HTXRD for these ALD VO $\mathrm{VO}_{x}$ films. An amorphous ALD $\mathrm{VO}_{x}$ film (approximately $60 \mathrm{~nm}$ in thickness) was heated from room temperature to $800{ }^{\circ} \mathrm{C}$ with a temperature ramping rate of $10{ }^{\circ} \mathrm{C} / \mathrm{min}$. During the heating process, XRD spectra were taken in steps of $50{ }^{\circ} \mathrm{C}$ from $200{ }^{\circ} \mathrm{C}$. As the results shown in Fig. 7, the XRD spectra started to show pronounced crystalline $\mathrm{VO}_{2}$ peaks at $600{ }^{\circ} \mathrm{C}$, suggesting that the film crystallization probably occurred at $550-600{ }^{\circ} \mathrm{C}$. Based on the HTXRD results, we performed another ex situ annealing experiment at $600{ }^{\circ} \mathrm{C}$. However, the annealed film was still discontinuous, with almost identical island morphology as after $800{ }^{\circ} \mathrm{C}$ annealing [Fig. 6(b)]. As Peter et al. ${ }^{31}$ and Rampelberg et al. ${ }^{39}$ both pointed out, besides annealing temperature, $\mathrm{O}_{2}$ partial pressure was also a critical factor to maintain the continuity of $\mathrm{VO}_{x}$ films after annealing. We therefore 

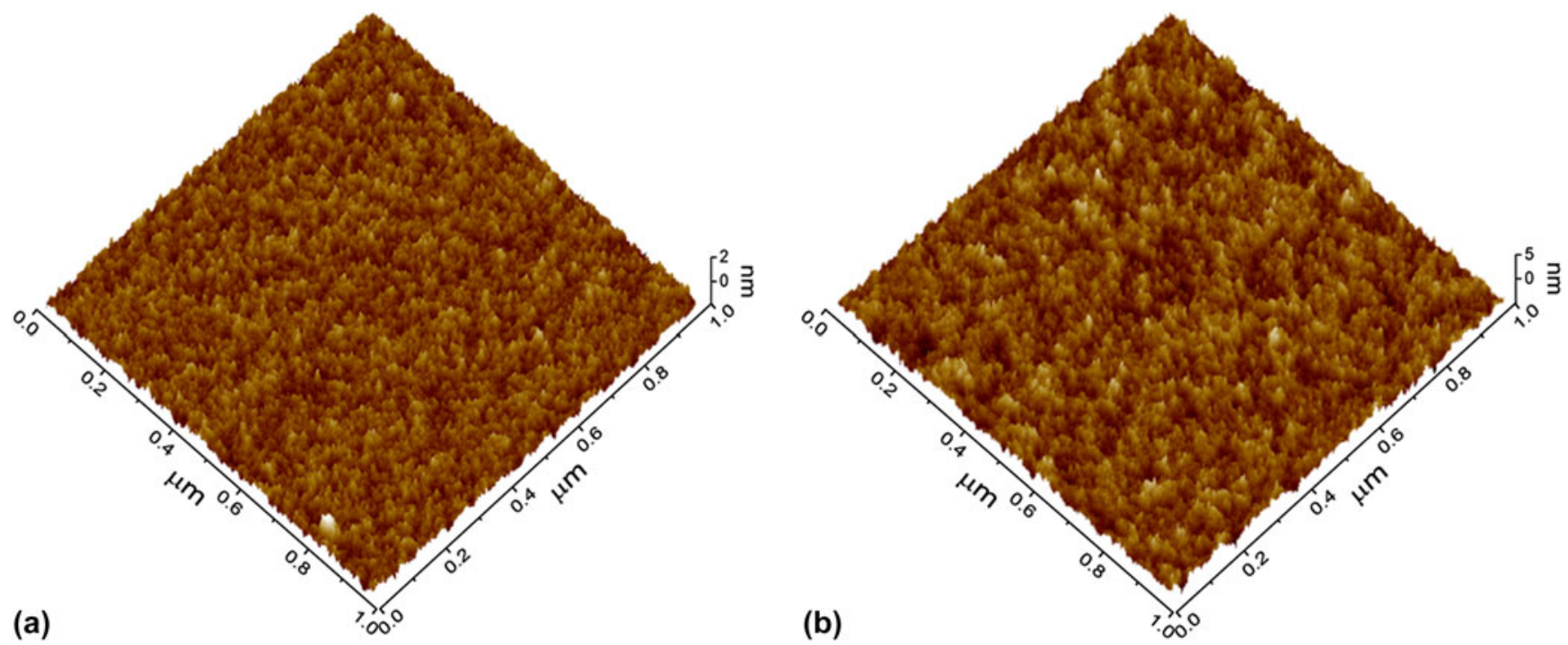

FIG. 4. Representative AFM images for $\mathrm{ALD} \mathrm{VO}_{x}$ films deposited (a) with $\mathrm{H}_{2} \mathrm{O}$ at $120{ }^{\circ} \mathrm{C}$ and (b) with $\mathrm{O}_{3}$ at $80{ }^{\circ} \mathrm{C}$, respectively. The film thicknesses were both $\sim 10 \mathrm{~nm}$, and the corresponding rms roughness values were (a) $0.32 \mathrm{~nm}$ and (b) $0.96 \mathrm{~nm}$, respectively.

suspected that the lack of $\mathrm{O}_{2}$ control in our annealing ambient was perhaps the reason for agglomeration, although further experiments are needed to confirm this.

On the other hand, understanding surface reaction mechanism is of great importance for an ALD process. ${ }^{33}$ To elucidate the mechanism involved in this $\mathrm{VO}_{x}$ ALD process, we further performed in situ QCM experiments to monitor the growth behavior of $\mathrm{VO}_{x}$ using $\mathrm{H}_{2} \mathrm{O}$ as the oxygen source. The QCM experiments were performed at $50{ }^{\circ} \mathrm{C}$ using the same recipe as that for the film depositions. The dosing times for $\mathrm{V}(\mathrm{dma})_{4}$ and $\mathrm{H}_{2} \mathrm{O}$ were both $1 \mathrm{~s}$, and the purging times after each precursor dose were all $100 \mathrm{~s}$. Figure 8(a) displays the mass gain on the QCM sensor during 50 cycles of ALD. The mass gain showed a generally linear behavior with deposition time, suggesting a well-behaved linear growth for this ALD process. To further analyze the mass gain, an enlarged view for three consecutive ALD cycles was representatively plotted in Fig. 8(b). The mass gain showed a jump increase when $\mathrm{V}(\mathrm{dma})_{4}$ or $\mathrm{H}_{2} \mathrm{O}$ was dosed into the chamber, and then gradually decayed and flattened out during the following purging step. The jump increase should correspond to the chemical reactions occurred on the surface, and the following decay process was likely due to the desorption of the physisorbed excess $\mathrm{V}(\mathrm{dma})_{4}$ or $\mathrm{H}_{2} \mathrm{O}$, or the byproduct dimethylamine molecules. Since we used a fairly low deposition temperature of $50{ }^{\circ} \mathrm{C}$, the molecule desorption rate was relatively slow. It should be noted that the spike-like signals when dosing $\mathrm{V}(\mathrm{dma})_{4}$ were probably interfered with the temperature effect, since the high-pressure assisting gas could suddenly fluctuate the sensor temperature and change the apparent mass reading on QCM. $^{40}$ However, this

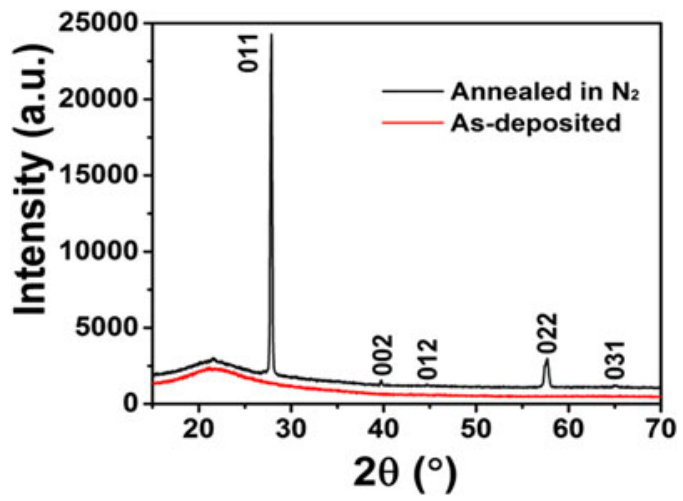

FIG. 5. XRD spectra of an ALD $\mathrm{VO}_{x}$ film before and after thermal annealing at $800{ }^{\circ} \mathrm{C}$ under $\mathrm{N}_{2}$ ambient for $2 \mathrm{~h}$. The as-deposited film (i.e., before annealing) did not show any XRD peaks (the broad feature at $20^{\circ}-25^{\circ}$ was from the fused silica substrate); whereas the annealed film showed pronounced XRD peaks which well matched with the pattern of monoclinic $\mathrm{VO}_{2}$ (PDF\#44-0252). The ALD $\mathrm{VO}_{x}$ film was originally deposited at $50{ }^{\circ} \mathrm{C}$ with $\mathrm{H}_{2} \mathrm{O}$, and the thickness was $\sim 60 \mathrm{~nm}$.

temperature effect should last only for a few seconds in our system [control experiments were performed without supplying $\left.\mathrm{V}(\mathrm{dma})_{4}\right]$, and, therefore, the following decay, which lasted for several tens of seconds, was indeed caused by the change of mass on the QCM sensor.

From the QCM curve [Fig. 8(a)], we further extracted the mass changes for each ALD cycle $\left(m_{0}\right)$ and each vanadium half cycle $\left(m_{1}\right)$, and plotted $m_{0}$ and $m_{1} / m_{0}$ ratios in Fig. 8(c). The mass gain for each ALD cycle $\left(m_{0}\right)$ was quite constant at around $1.37 \pm 0.13 \mathrm{~Hz}$, which again indicated a constant per cycle growth rate for this ALD process. The $m_{1} / m_{0}$ ratio was also quite constant at 


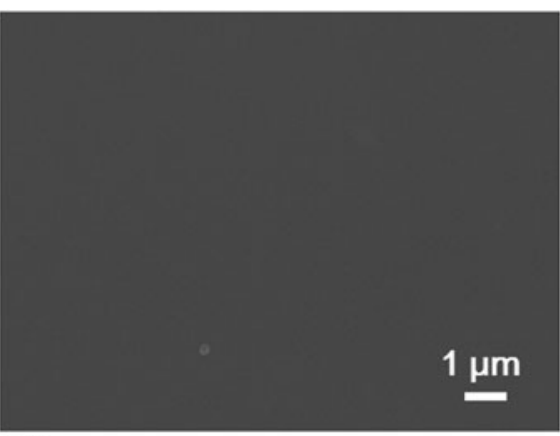

(a)

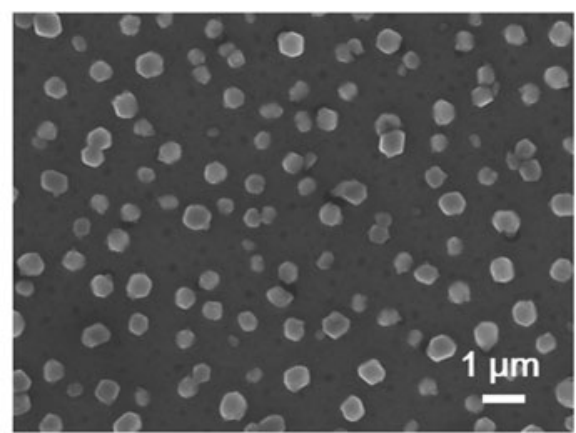

(b)

FIG. 6. SEM top-view images comparatively showing the accompanying morphological change of the $\mathrm{VO}_{x}$ film (a) before and (b) after the annealing process as described in Fig. 5.

around $1.01 \pm 0.05$, which suggested that the surface reaction chemistry was consistent over the entire deposition time. The $m_{1} / m_{0}$ ratio can be further used to analyze the surface reaction mechanism. ${ }^{41}$ As dimethylamino metal precursors are commonly suggested to follow ligand-exchange mechanisms, ${ }^{42-44}$ we first assume that this ALD $\mathrm{VO}_{x}$ process follows a simple ligand-exchange mechanism, and the associated two half-cycle reactions are rewritten as the following:

$$
\begin{aligned}
& \mid-(\mathrm{OH})_{y}+\mathrm{V}\left(\mathrm{N}\left(\mathrm{CH}_{3}\right)_{2}\right)_{4}(\mathrm{~g}) \rightarrow \\
& \quad \mid-\mathrm{O}_{y} \mathrm{~V}\left(\mathrm{~N}\left(\mathrm{CH}_{3}\right)_{2}\right)_{4-y}+y \mathrm{NH}\left(\mathrm{CH}_{3}\right)_{2}(\mathrm{~g}), \\
& \mid-\mathrm{O}_{y} \mathrm{~V}\left(\mathrm{~N}\left(\mathrm{CH}_{3}\right)_{2}\right)_{4-y}+2 \mathrm{H}_{2} \mathrm{O}(\mathrm{g}) \rightarrow \\
& \quad \mid-\left(\mathrm{VO}_{2}\right)(\mathrm{OH})_{y}+(4-y) \mathrm{NH}\left(\mathrm{CH}_{3}\right)_{2}(\mathrm{~g}),
\end{aligned}
$$

where the symbols " - " and " $(\mathrm{g})$ " denote the surface and gaseous compounds, respectively. In Eq. (1a), a V(dma) molecule reacts with $y$ number of surface hydroxyl groups, and affords $y$ numbers of $\mathrm{V}-\mathrm{O}$ bonds on surface and $y$ numbers of gaseous dimethylamine molecules. Notice that $(4-y)$ number of dimethylamino ligands are still attached on the vanadium at the end of the first (vanadium) half cycle. These attached dimethylamino ligands will react with $\mathrm{H}_{2} \mathrm{O}$ in the second (water) half cycle, following Eq. (1b), and afford surface hydroxyl groups at the end. Thus, according to Eqs. (1a) and (1b), the mass gain ratio, $m_{1} / m_{0}$, should be equal to (227 45y)/83. Plugging in the experimental data, $y$ is calculated as 3.18 , implying that $3.18 / 4$ (or $\sim 80 \%$ ) of dimethylamino groups are released in the vanadium half cycle. It should be noted that the surface dimethylamino groups can also possibly undergo partial decomposition to form methyleneamino groups, as observed for other dimethylamino metal precursors. ${ }^{42,45}$ If we arbitrarily assume that this decomposition is $100 \%$ in our case, the equations should be rewritten as the following:

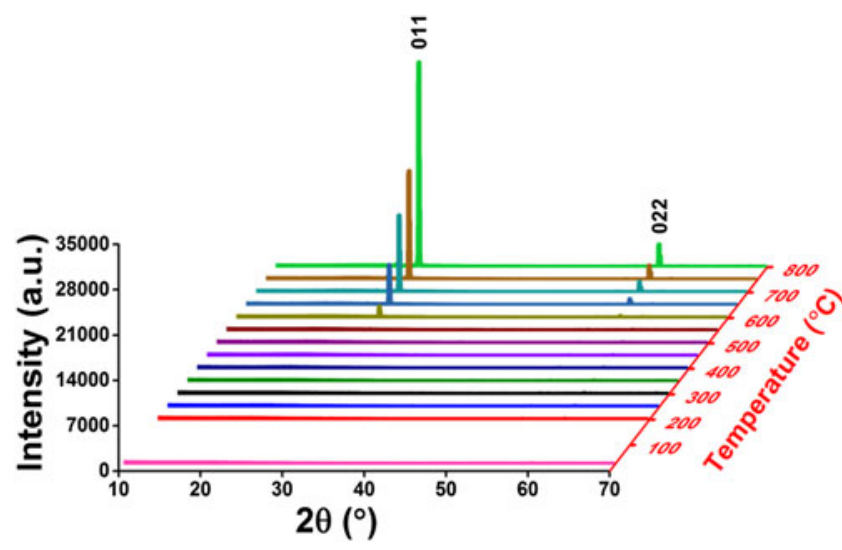

FIG. 7. In situ HTXRD for an ALD $\mathrm{VO}_{x}$ film heated from room temperature to $800{ }^{\circ} \mathrm{C}$, with the XRD spectra taken in steps of $50{ }^{\circ} \mathrm{C}$ from $200{ }^{\circ} \mathrm{C}$. The XRD spectra started to show pronounced crystalline $\mathrm{VO}_{2}$ peaks at $600{ }^{\circ} \mathrm{C}$.

$$
\begin{aligned}
& \mid-(\mathrm{OH})_{y^{\prime}}+\mathrm{V}\left(\mathrm{N}\left(\mathrm{CH}_{3}\right)_{2}\right)_{4}(\mathrm{~g}) \rightarrow \\
& \quad \mid-\mathrm{O}_{y^{\prime}} \mathrm{V}\left(\mathrm{N}=\mathrm{CH}_{2}\right)_{4-y^{\prime}}+\left(4-y^{\prime}\right) \mathrm{CH}_{4}(\mathrm{~g}) \\
& \quad+y^{\prime} \mathrm{NH}\left(\mathrm{CH}_{3}\right)_{2}(\mathrm{~g}), \\
& \mid-\mathrm{O}_{y^{\prime}} \mathrm{V}\left(\mathrm{N}=\mathrm{CH}_{2}\right)_{4-y^{\prime}}+2 \mathrm{H}_{2} \mathrm{O}(\mathrm{g}) \rightarrow \\
& \quad \mid-\left(\mathrm{VO}_{2}\right)(\mathrm{OH})_{y^{\prime}}+\left(4-y^{\prime}\right) \mathrm{NH}=\mathrm{CH}_{2}(\mathrm{~g}),
\end{aligned}
$$

where $y^{\prime}$ is used to distinguish from $y$ as previously used in Eqs. (1a) and (1b). With similar analysis as above, $y^{\prime}$ is calculated as 2.73 , corresponding to $\sim 68 \%$ of dimethylamino groups released in the vanadium half cycle. The real case for $y$ (or $y^{\prime}$ ) should be expected to be between 2.73 and 3.18. To find out the exact percentage of decomposition, one would probably need some other in situ techniques, such as in situ XPS. ${ }^{46}$ But, nevertheless, the value for $y\left(\right.$ or $\left.y^{\prime}\right)$ is fairly high (roughly 3 ), implying that approximately three surface hydroxyl groups are needed to react with each $\mathrm{V}(\mathrm{dma})_{4}$ molecule in the vanadium half cycle. 

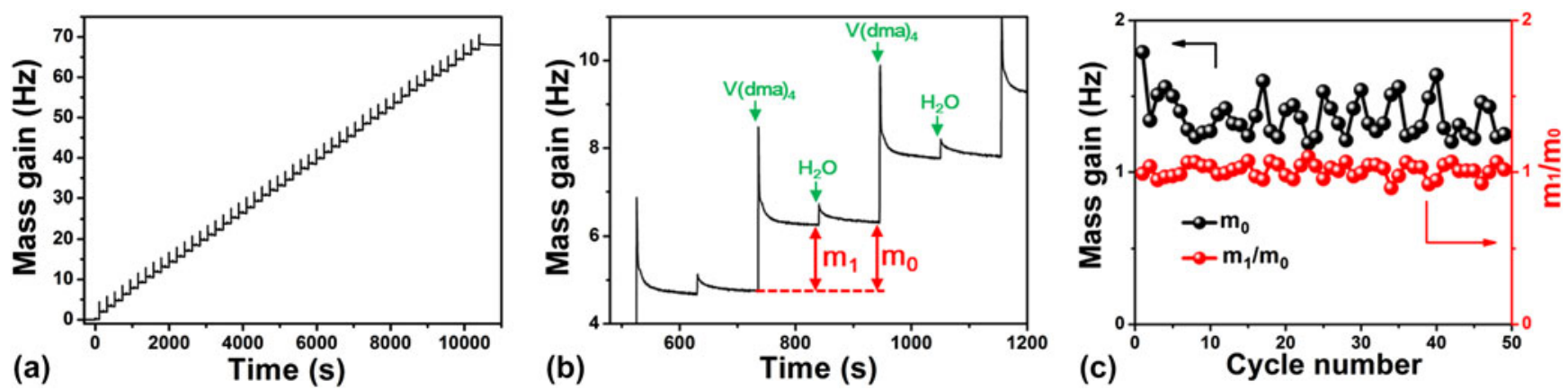

FIG. 8. In situ QCM measurements for $\mathrm{ALD} \mathrm{VO}_{x}$ at $50{ }^{\circ} \mathrm{C}$. (a) Mass gain versus time for $50 \mathrm{ALD}$ cycles. (b) Enlarged view for three consecutive ALD cycles. (c) Per cycle mass gain $\left(m_{0}\right)$ and $m_{1} / m_{0}$ ratio extracted for each individual ALD cycle.

\section{CONCLUSIONS}

In summary, we performed a comprehensive study of ALD for $\mathrm{VO}_{x}$ thin films using tetrakis(dimethylamino) vanadium [i.e., $\mathrm{V}(\mathrm{dma})_{4}$ ] as the vanadium precursor. The $\mathrm{V}(\mathrm{dma})_{4}$ precursor was highly volatile, and therefore no additional precursor heating was needed for deposition. Both $\mathrm{H}_{2} \mathrm{O}$ and $\mathrm{O}_{3}$ were investigated as the coreactant for depositing $\mathrm{VO}_{x}$. The deposition temperature was explored from 50 to $200{ }^{\circ} \mathrm{C}$. The film growth rates remained fairly constant up to $120{ }^{\circ} \mathrm{C}$, but substantially increased above $160{ }^{\circ} \mathrm{C}$, which was likely due to partial thermal decomposition at higher temperatures. Below $120{ }^{\circ} \mathrm{C}$, the $\mathrm{VO}_{x}$ growth rate using $\mathrm{O}_{3}$ was $\sim 0.045 \mathrm{~nm} /$ cycle, and the growth rate using $\mathrm{H}_{2} \mathrm{O}$ was $\sim 0.030 \mathrm{~nm} /$ cycle. Careful material characterizations were performed on the ALD $\mathrm{VO}_{x}$ films. The deposited films were found fairly pure, with the impurity levels for $\mathrm{C}$ and $\mathrm{N}$ both below 3 at.\%. All the as-deposited films were amorphous and smooth. Postdeposition annealing under $\mathrm{N}_{2}$ ambient could crystallize the asdeposited films to monoclinic $\mathrm{VO}_{2}$ phase. In situ HTXRD suggested that the minimum temperature needed for film crystallization was at around $550-600{ }^{\circ} \mathrm{C}$. However, annealing (at either 600 or $800{ }^{\circ} \mathrm{C}$ ) could lead to severe film agglomeration, and as a result, the annealed films were no longer continuous and formed submicron-sized islands. In situ mechanism study using QCM was also performed to analyze the surface reaction chemistry during ALD. The QCM results showed that the $\mathrm{VO}_{x}$ film growth followed a consistently linear growth, and each $\mathrm{V}(\mathrm{dma})_{4}$ molecule was suggested to react with approximately three surface hydroxyl groups in the vanadium half cycle during ALD.

\section{ACKNOWLEDGMENTS}

This work was financially supported by NSFC (Grant No. 51302007), Guangdong Natural Science Funds for Distinguished Young Scholar (Grant No. 2015A030306036), and Shenzhen Science and Technology Innovation Committee (Grant Nos. JCYJ20140417144423201 and KQCX20150327093155293).

\section{REFERENCES}

1. C.H. Griffiths and H.K. Eastwood: Influence of stoichiometry on the metal-semiconductor transition in vanadium dioxide. J. Appl. Phys. 45(5), 2201 (1974).

2. F.J. Morin: Oxides which show a metal-to-insulator transition at the Neel temperature. Phys. Rev. Lett. 3(1), 34 (1959).

3. M-J. Lee, Y. Park, D-S. Suh, E-H. Lee, S. Seo, D-C. Kim, R. Jung, B-S. Kang, S-E. Ahn, C.B. Lee, D.H. Seo, Y-K. Cha, I-K. Yoo, J-S. Kim, and B.H. Park: Two series oxide resistors applicable to high speed and high density nonvolatile memory. Adv. Mater. 19(22), 3919 (2007).

4. J. Jeong, N. Aetukuri, T. Graf, T.D. Schladt, M.G. Samant, and S.S.P. Parkin: Suppression of metal-insulator transition in $\mathrm{VO}_{2}$ by electric field-induced oxygen vacancy formation. Science 339(6126), 1402 (2013).

5. K. Appavoo, B. Wang, N.F. Brady, M. Seo, J. Nag, R.P. Prasankumar, D.J. Hilton, S.T. Pantelides, and R.F. Haglund: Ultrafast phase transition via catastrophic phonon collapse driven by plasmonic hotelectron injection. Nano Lett. 14(3), 1127 (2014).

6. X. Chen, H. Zhu, Y-C. Chen, Y. Shang, A. Cao, L. Hu, and G.W. Rubloff: MWCNT/ $\mathrm{V}_{2} \mathrm{O}_{5}$ core/shell sponge for high areal capacity and power density Li-Ion cathodes. ACS Nano 6(9), 7948 (2012).

7. V. Raju, J. Rains, C. Gates, W. Luo, X. Wang, W.F. Stickle, G.D. Stucky, and X. Ji: Superior cathode of sodium-ion batteries: Orthorhombic $\mathrm{V}_{2} \mathrm{O}_{5}$ nanoparticles generated in nanoporous carbon by ambient hydrolysis deposition. Nano Lett. 14(7), 4119 (2014).

8. I.E. Rauda, V. Augustyn, L.C. Saldarriaga-Lopez, X. Chen, L.T. Schelhas, G.W. Rubloff, B. Dunn, and S.H. Tolbert: Nanostructured pseudocapacitors based on atomic layer deposition of $\mathrm{V}_{2} \mathrm{O}_{5}$ onto conductive nanocrystal-based mesoporous ITO scaffolds. Adv. Funct. Mater. 24, 6717 (2014).

9. S. Boukhalfa, K. Evanoff, and G. Yushin: Atomic layer deposition of vanadium oxide on carbon nanotubes for high-power supercapacitor electrodes. Energy Environ. Sci. 5(5), 6872 (2012).

10. D.X. Long, Y. Xu, S-J. Kang, W-T. Park, E-Y. Choi, Y-C. Nah, C. Liu, and Y-Y. Noh: Solution processed vanadium pentoxide as charge injection layer in polymer field-effect transistor with Mo electrodes. Org. Electron. 17, 66 (2015).

11. J. Keränen, C. Guimon, E. Iiskola, A. Auroux, and L. Niinistö: Atomic layer deposition and surface characterization of highly dispersed titania/silica-supported vanadia catalysts. Catal. Today 78(1-4), 149 (2003).

12. N. Ozer: Electrochemical properties of sol-gel deposited vanadium pentoxide films. Thin Solid Films 305, 80 (1997).

13. A.A. Akl: Thermal annealing effect on the crystallization and optical dispersion of sprayed $\mathrm{V}_{2} \mathrm{O}_{5}$ thin films. J. Phys. Chem. Solids 71(3), 223 (2010). 
14. A. Ghosh, E.J. Ra, M. Jin, H-K. Jeong, T.H. Kim, C. Biswas, and Y.H. Lee: High pseudocapacitance from ultrathin $\mathrm{V}_{2} \mathrm{O}_{5}$ films electrodeposited on self-standing carbon-nanofiber paper. $A d v$. Funct. Mater. 21(13), 2541 (2011).

15. S.A. Hakim, Y. Liu, G.S. Zakharova, and W. Chen: Synthesis of vanadium pentoxide nanoneedles by physical vapour deposition and their highly sensitive behavior towards acetone at room temperature. RSC Adv. 5(30), 23489 (2015).

16. Y. Cui, X. Wang, Y. Zhou, R. Gordon, and S. Ramanathan: Synthesis of vanadium dioxide thin films on conducting oxides and metal-insulator transition characteristics. J. Cryst. Growth 338(1), 96 (2012).

17. R.J. Smith, C.V. Ramana, O.M. Hussain, C.C. Chusuei, and C.M. Julien: Correlation between growth conditions, microstructure, and optical properties in pulsed-laser-deposited $\mathrm{V}_{2} \mathrm{O}_{5}$ thin films. Chem. Mater. 17, 1213 (2005).

18. N.K. Nandakumar and E.G. Seebauer: Low temperature chemical vapor deposition of nanocrystalline $\mathrm{V}_{2} \mathrm{O}_{5}$ thin films. Thin Solid Films 519(11), 3663 (2011).

19. J.S. Daubert, N.P. Lewis, H.N. Gotsch, J.Z. Mundy, D.N. Monroe, E.C. Dickey, M.D. Losego, and G.N. Parsons: Effect of meso- and micro-porosity in carbon electrodes on atomic layer deposition of pseudocapacitive $\mathrm{V}_{2} \mathrm{O}_{5}$ for high performance supercapacitors. Chem. Mater. 27(19), 6524 (2015).

20. E. Østreng, K.B. Gandrud, Y. Hu, O. Nilsen, and H. Fjellvåg: High power nano-structured $\mathrm{V}_{2} \mathrm{O}_{5}$ thin film cathodes by atomic layer deposition. J. Mater. Chem. A 2(36), 15044 (2014).

21. J.C. Badot, A. Mantoux, N. Baffier, O. Dubrunfaut, and D. Lincot: Electrical properties of $\mathrm{V}_{2} \mathrm{O}_{5}$ thin films obtained by atomic layer deposition (ALD). J. Mater. Chem. 14(23), 3411 (2004).

22. X. Chen, E. Pomerantseva, P. Banerjee, K. Gregorczyk, R. Ghodssi, and G. Rubloff: Ozone-based atomic layer deposition of crystalline $\mathrm{V}_{2} \mathrm{O}_{5}$ films for high performance electrochemical energy storage. Chem. Mater. 24(7), 1255 (2012).

23. J. Musschoot, D. Deduytsche, H. Poelman, J. Haemers, R.L. Van Meirhaeghe, S. Van den Berghe, and C. Detavernier: Comparison of thermal and plasma-enhanced ALD/CVD of vanadium pentoxide. J. Electrochem. Soc. 156(7), 122 (2009).

24. M-G. Willinger, G. Neri, E. Rauwel, A. Bonavita, G. Micali, and N. Pinna: Vanadium oxide sensing layer grown on carbon nanotubes by a new atomic layer deposition process. Nano Lett. 8(12), 4201 (2008).

25. I.M. Povey, M. Bardosova, F. Chalvet, M.E. Pemble, and H.M. Yates: Atomic layer deposition for the fabrication of 3D photonic crystals structures: Growth of $\mathrm{Al}_{2} \mathrm{O}_{3}$ and $\mathrm{VO}_{2}$ photonic crystal systems. Surf. Coat. Technol. 201(22-23), 9345 (2007).

26. P. Dagur, A.U. Mane, and S.A. Shivashankar: Thin films of $\mathrm{VO}_{2}$ on glass by atomic layer deposition: Microstructure and electrical properties. J. Cryst. Growth 275(1-2), e1223 (2005).

27. E. Østreng, O. Nilsen, and H. Fjellvåg: Optical properties of vanadium pentoxide deposited by ALD. J. Phys. Chem. C 116(36), 19444 (2012).

28. T. Blanquart, J. Niinisto, M. Gavagnin, V. Longo, M. Heikkila, E. Puukilainen, V.R. Pallem, C. Dussarrat, M. Ritala, and M. Leskela: Atomic layer deposition and characterization of vanadium oxide thin films. RSC Adv. 3(4), 1179 (2013).

29. G. Rampelberg, M. Schaekers, K. Martens, Q. Xie, D. Deduytsche, B. De Schutter, N. Blasco, J. Kittl, and C. Detavernier: Semiconductor-metal transition in thin $\mathrm{VO}_{2}$ films grown by ozone based atomic layer deposition. Appl. Phys. Lett. 98(16), 162902 (2011).

30. P.A. Premkumar, M. Toeller, I.P. Radu, C. Adelmann, M. Schaekers, J. Meersschaut, T. Conard, and S.V. Elshocht: Process study and characterization of $\mathrm{VO}_{2}$ thin films synthesized by ALD using TEMAV and $\mathrm{O}_{3}$ precursors. ECS J. Solid State Sci. Technol. 1(4), 169 (2012).

31. A.P. Peter, K. Martens, G. Rampelberg, M. Toeller, J.M. Ablett, J. Meersschaut, D. Cuypers, A. Franquet, C. Detavernier, J-P. Rueff, M. Schaekers, S. Van Elshocht, M. Jurczak, C. Adelmann, and I.P. Radu: Metal-insulator transition in ALD $\mathrm{VO}_{2}$ ultrathin films and nanoparticles: Morphological control. Adv. Funct. Mater. 25(5), 679 (2015).

32. Y. Gao, Y. Shao, L. Yan, H. Li, Y. Su, H. Meng, and X. Wang: Efficient charge injection in organic field-effect transistors enabled by low-temperature atomic layer deposition of ultrathin $\mathrm{VO}_{x}$ interlayer. Adv. Funct. Mater. 26(25), 4456 (2016).

33. S.M. George: Atomic layer deposition: An overview. Chem. Rev. 110(1), 111 (2010).

34. H. Li, Y. Gao, Y. Shao, Y. Su, and X. Wang: Vapor-phase atomic layer deposition of $\mathrm{Co}_{9} \mathrm{~S}_{8}$ and its application for supercapacitors. Nano Lett. 15(10), 6689 (2015).

35. H-J. Son, X. Wang, C. Prasittichai, N.C. Jeong, T. Aaltonen, R.G. Gordon, and J.T. Hupp: Glass-encapsulated light Harvesters: More efficient dye-sensitized solar cells by deposition of selfaligned, conformal, and self-limited silica layers. J. Am. Chem. Soc. 134(23), 9537 (2012).

36. J.J. Gu, X. Wang, H. Wu, R.G. Gordon, and P.D. Ye: Variability improvement by interface passivation and EOT scaling of InGaAs nanowire MOSFETs. IEEE Electron Device Lett. 34(5), 608 (2013).

37. A. Benayad, H. Martinez, A. Gies, B. Pecquenard, A. Levasseur, and D. Gonbeau: XPS investigations achieved on the first cycle of $\mathrm{V}_{2} \mathrm{O}_{5}$ thin films used in lithium microbatteries. J. Electron Spectrosc. Relat. Phenom. 150(1), 1 (2006).

38. H. Li, Y. Shao, Y. Su, Y. Gao, and X. Wang: Vapor-phase atomic layer deposition of nickel sulfide and its application for efficient oxygen-evolution electrocatalysis. Chem. Mater. 28(4), 1155 (2016).

39. G. Rampelberg, D. Deduytsche, B. De Schutter, P.A. Premkumar, M. Toeller, M. Schaekers, K. Martens, I. Radu, and C. Detavernier: Crystallization and semiconductor-metal switching behavior of thin $\mathrm{VO}_{2}$ layers grown by atomic layer deposition. Thin Solid Films 550, 59 (2014).

40. M.N. Rocklein and S.M. George: Temperature-induced apparent mass changes observed during quartz crystal microbalance measurements of atomic layer deposition. Anal. Chem. 75(19), 4975 (2003).

41. Z. Guo, H. Li, Q. Chen, L. Sang, L. Yang, Z. Liu, and X. Wang: Low-temperature atomic layer deposition of high purity, smooth, low resistivity copper films by using amidinate precursor and hydrogen plasma. Chem. Mater. 27(17), 5988 (2015).

42. X. Meng, J.A. Libera, T.T. Fister, H. Zhou, J.K. Hedlund, P. Fenter, and J.W. Elam: Atomic layer deposition of gallium sulfide films using hexakis(dimethylamido)digallium and hydrogen sulfide. Chem. Mater. 26(2), 1029 (2014).

43. J.W. Elam, D.A. Baker, A.J. Hryn, A.B.F. Martinson, M.J. Pellin, and J.T. Hupp: Atomic layer deposition of tin oxide films using tetrakis(dimethylamino) tin. J. Vac. Sci. Technol., A 26(2), 244 (2008).

44. D.M. Hausmann, E. Kim, J. Becker, and R.G. Gordon: Atomic layer deposition of hafnium and zirconium oxides using metal amide precursors. Chem. Mater. 14, 4350 (2002).

45. B.B. Burton, S.W. Kang, S.W. Rhee, and S.M. George: $\mathrm{SiO}_{2}$ atomic layer deposition using tris(dimethylamino)silane and hydrogen peroxide studied by in situ transmission FTIR spectroscopy. J. Phys. Chem. C 113(19), 8249 (2009).

46. Q. Ma, H. Guo, R.G. Gordon, and F. Zaera: Surface chemistry of copper(I) acetamidinates in connection with atomic layer deposition (ALD) processes. Chem. Mater. 23(14), 3325 (2011). 